\title{
Understanding the Logic of Climate Change Adaptation: Unpacking Barriers to Climate Change Adaptation by Smallholder Farmers in Chimanimani District, Zimbabwe
}

\author{
Wisemen Chingombe ${ }^{1, *(D)}$ and Happwell Musarandega ${ }^{2}$ \\ 1 School of Biology and Environmental Sciences, University of Mpumalanga, Private Bag X11283, \\ Mbombela 1200, South Africa \\ 2 Department of Geography and Environmental Science, University of Fort Hare, Private Bag X1314, \\ Alice 5700, South Africa; hmusarandega@gmail.com \\ * Correspondence: Wisemen.Chingombe@ump.ac.za
}

check for updates

Citation: Chingombe, W.; Musarandega, H. Understanding the Logic of Climate Change Adaptation: Unpacking Barriers to Climate

Change Adaptation by Smallholder Farmers in Chimanimani District, Zimbabwe. Sustainability 2021, 13, 3773. https://doi.org/10.3390/ su13073773

Academic Editor: Luca Salvati

Received: 15 October 2020

Accepted: 2 December 2020

Published: 29 March 2021

Publisher's Note: MDPI stays neutral with regard to jurisdictional claims in published maps and institutional affiliations.

Copyright: (c) 2021 by the authors. Licensee MDPI, Basel, Switzerland. This article is an open access article distributed under the terms and conditions of the Creative Commons Attribution (CC BY) license (https:/ / creativecommons.org/licenses/by/ $4.0 /)$.

\begin{abstract}
Smallholder farmers in Chimanimani District, Zimbabwe, have grappled for a long time with the effects of climate change despite the locally and externally driven resilience-building initiatives in place. This paper adopts a qualitative approach to explore the encountered adaptation barriers. Smallholder farmers, Agricultural Technical and Extension Services (AGRITEX) officers, and the traditional leadership fraternity were randomly selected from the district's 22 rural wards as study participants. Data were solicited using focus group discussions and face-to-face interviews that were corroborated by researcher observation methods. The data were analysed using thematic content analysis of key perspectives drawn from smallholder farmers, traditional leaders, and extension officers who work with farmers. What was unveiled is an assortment of barrier dynamics related to climate, finance, infrastructure, generational change, water resources, inefficient bureaucracy, gender inequality, and health barriers. Vensim PLE 7.3 software was used to illustrate barrier components as they act together to cripple smallholder farmers' efforts to raise their adaptive capacity. Adaptation barriers are complex and, therefore, cannot be addressed using policies that are fragmented. The paper recommends a multidimensional approach by policy makers to analyse adaptive barriers to build more climate resilience within smallholder farmer communities.
\end{abstract}

Keywords: climate change adaptation; adaptation barrier; smallholder farmers; adaptive capacity

\section{Introduction}

As climate change continues to take a toll on various global settings, smallholder farmers, particularly in the developing world, increasingly become a vulnerable population group [1]. Climate change mitigation comes with high costs and complex challenges such that adaptation to the phenomenon is a viable option [2-4]. According to the Intergovernmental Panel on Climate Change (IPCC) [3], climate change adaptation refers to "adjustment to actual or expected climate and its effects". Adaptation aims to "moderate or avoid harm or exploit beneficial opportunities". It generally means a shift in livelihood practices meant to cope with newly emerging climatic conditions. It is an ongoing process with no specific endpoint [5].

Climate change adaptation is also viewed as a way of reducing vulnerability, increasing resilience, moderating the risk of climate impacts on lives and livelihoods, and taking advantage of the opportunities posed by actual or expected climate change [4]. Thus, smallholder farmers' productivity depends on how effectively they adapt to their physical environment in the wake of climate change.

In their quest to adapt to the changing pattern of climate, smallholder farmers face a wide range of barriers. According to the Productivity Commission [6], barriers to climate change adaptation refer to circumstances that "restrict people's ability to identify, 
evaluate or manage risks in a way that delivers the highest level of community wellbeing". Eisenack et al. [2] defined adaptation barriers as those impediments to specific actions needed to fulfil the goals of particular actors.

In this paper, a wide range of earlier research on adaptation barriers drawn from context-based studies and an extensive review of literature is acknowledged. The Productivity Commission [7] cited market failures, policy and regulatory barriers, governance and institutional barriers, behavioural and cognitive barriers as common inhibiting factors. Antwi-Agyei et al. [8] explored case studies drawn from northeastern Ghana supplemented by a systematic review of the literature to evaluate the barriers that hamper operational enactment of climate adaptations in the sub-Saharan African region. Doughty-Grajales [9] analysed adaptation barriers in Vietnam using an institutional approach based on water management, agriculture floods, and drought management sectors, and concluded that information, communication, leadership, finance, gender issues, human resources, and ineffective forecasting were the key barriers.

Biesbroek [10] reviewed 81 papers that analysed adaptation in developing nations and highlighted that a third of these concurrently identified barriers were related to high vulnerability, low levels of adaptive capacity, weak institutional environments, with most of these barriers being exacerbated by the prevalence of non-climatic socioeconomic factors such as inequality, inequity, religious tensions, and poverty. In its overall assessment, the IPCC [3] asserted that the key impeding factors revolve around, inter alia, limited availability of financial and human resources; incomplete governance coordination; lack of adequate research on climate change; extreme weather; and ineffective monitoring tools for climate change adaptation.

The methods that have been used to analyse adaptation barriers in literature are not exhaustive. Barnett et al. [11] asserted that barriers are context-specific. Again, they are born out of trade-offs amid competing goals within the adaptation decision-making process [2]. Adaptation decisions differ from place to place. To date, there seems to be no agreed framework to understand the proximate causes and complexity of climate change adaptation barriers because of the subtleness of the boundaries between suggested categories [2,8,10,12]. Brown et al. [13], as cited in Biesbroek [10], alluded that there is an absence of a conventional framing of barriers to climate change since they are entrenched in and are an outcome of highly flexible and multifaceted socio-cultural progressions. More practical and evidence-based studies need to be done to establish their proximate drivers and the connectedness of the commonly recognised barriers.

Whilst barriers to climate change adaptation have been studied in various settings, their uniqueness of prevalence and connectedness call for more studies to be done. We did not find specific studies done in the district to reveal the unique climate change adaptation barriers encountered by smallholder farmers in their localised settings. It remains unclear as to how adaptation barriers relate to one another to create a complex network of barriers that derail local and external intervention initiatives towards improving the adaptive capacity of the farmers.

Therefore, this paper uses an inductive approach together with existing literature on climate change adaptation barriers $[2,8,10,13]$ to facilitate a conceptualisation of climate change adaptation barriers. The objectives of the study are twofold: (1) to expose local area-based adaptation barriers to smallholder farming in Chimanimani District and (2) to depict the imperceptible connectedness between different adaptation barriers. Likewise, Section 3.1 of this paper reports on barriers with special emphasis on their exclusivity, despite the study wards being situated in the same district. We reveal that in a district with a geographical area of $3353 \mathrm{~km}^{2}$ [14], there is a uniqueness of challenges to climate change adaptation. In Section 3.2 we use a diagrammatic approach to illustrate the connectedness of the barriers, based on an interpretation of the sentiments drawn from different groups of respondents. The follow-up examples to the illustration help to demonstrate that, in the practical sense, some climate change adaptation barriers have connections that need to be considered for policy intervention purposes. 


\section{Methodological Plan}

\subsection{Description of the Study Area}

The study was done in Chimanimani District, Manicaland Province, in Zimbabwe (Figure 1). The district lies in the far southeastern part of Zimbabwe's border with Mozambique. It falls between the coordinates $32085^{\prime} 0.00^{\prime \prime} \mathrm{E}$ and $32088^{\prime} 0.00^{\prime \prime} \mathrm{E}$ and $19078^{\prime} 0.00^{\prime \prime} \mathrm{S}$ and $19081^{\prime} 0.00^{\prime \prime} \mathrm{S}$, with a geographical area of $3353 \mathrm{~km}^{2}$. The total population is 1,752,698 [15]. The district comprises 23 administrative wards [16]. For the sake of consistency, Ward 15 (Ngangu), which is the district's administration centre, was not considered for this study due to its outstanding urban characteristics, despite smallholder farming being practised by some residence. The eastern section is predominantly an area of rugged mountain terrain with over $1000 \mathrm{~mm}$ of annual rainfall. The western section is a low-lying, relatively dry belt that stretches into the Save River, receiving between $350-450 \mathrm{~mm}$ of annual rainfall [17]. Here, there is extreme inter- and intra-seasonal rainfall variability. Several irrigation schemes exist in the drier areas, such as Nyanyadzi (Ward 8), Chakohwa (Ward 3), Mutambara (Ward 4), and Mhandarume-Mashowani (Ward 2). In all these schemes, farmers draw water from nearby major rivers using open canals to irrigate their plots. Multiple fishery schemes were initiated in various parts of the district for additional livelihood sustenance. Nine fish ponds funded by World Vision were built at the Mhandarume-Mashowani irrigation scheme in Ward 3 near Wengezi. Chimanimani District has four chieftainship divisions administered by Chiefs Muusha, Mutambara, Chikukwa, and Ngorima. Each of these has at least two headmen and several village heads as part of the traditional leadership hierarchy.

\subsection{Methods}

The study was primarily qualitative and executed using a case study design. An inductive approach with much focus on mixed sampling was used to select respondents [18]. The adoption of an inductive approach did not negatively influence the results of the study because when studying barriers to climate change adaptation, one can obtain new insights not based on a specific pre-determined theory but from a systematic approach [19]. Likewise, multiple data sources [20] were triangulated to ascertain the views expressed by respondents in each case.

Peculiar ward and district-based data specifically to do with what each category of respondents mentioned as a barrier to climate change adaptation were gathered. The data findings were discussed based on existing literature accounts on climate change adaptation barriers $[2,8,10,13]$. Participants for the study were not chosen based on specifically designed or fixed samples, as in quantitative research [21], but purposively selected to explore smallholder farmers' in-depth awareness of local barriers.

To solicit data from the smallholder farmers, two (2) initial focus group discussions (FGDs) were conducted in each of the 22 wards. Long-serving Agricultural Technical and Extension Services (AGRITEX) officers helped the researchers to select smallholder farmer participants who were abundantly endowed with knowledge related to the local climate change history. A supplementary FGD session was rescheduled and administered in Wards $4,6,18,19$, and 20 to make a full complement. For this study, the rationale for running extra FGDs was defined by some outstanding characteristics that were twofold. Firstly, these were wards in which data saturation could not be attained from the scheduled two FGDs. Data saturation means a stage in the data collection process where no new insights emerge from respondents [19]. Secondly, extra FGDs were scheduled for those wards with outstanding population sizes, that is, Ward 13 (Charter) with 11,042 persons and Ward 16 (Gwindingwi) with 12,967 persons [16]. The focus group sizes ranged between 8-12 participants, a range previously applied in other studies [22]. With no specifically defined sex ratio for FGD composition, more female participants than their male counterparts were selected to participate in the study since females $(52 \%)$ outnumbered males $(48 \%)$ in the district. The only exceptions were in Wards 11,12 , and 14, where more male household heads than female household heads were found resident at smallholder farms. 
The FGD comprised elderly household head participants aged 50 years or more. These had a rich knowledge of the localised climate change scenario dating back 30 years plus rich experience in encountering the climate change adaptation barriers.

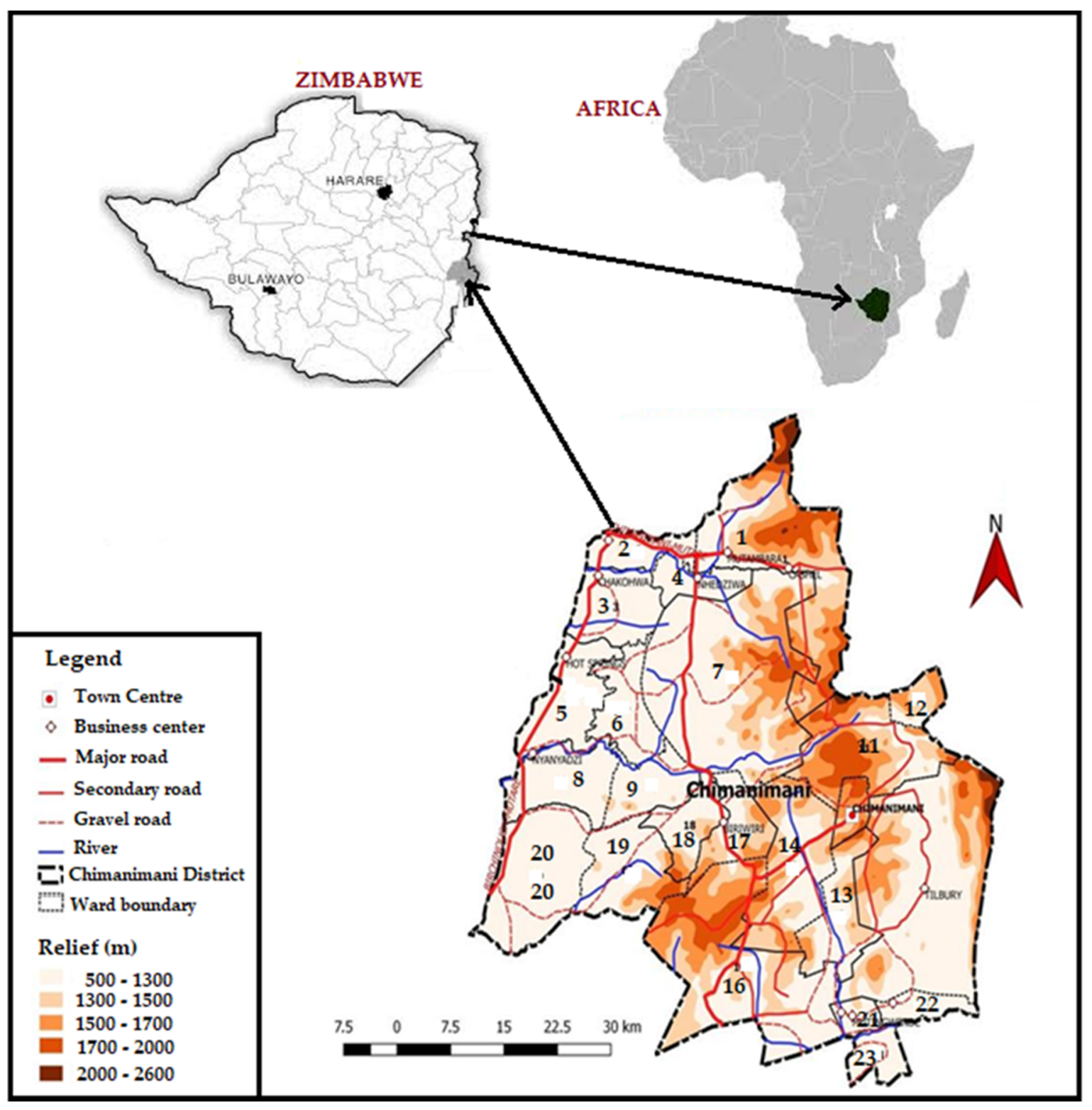

Figure 1. Study area map.

Two (2) senior extension officers (male and female), having worked for over five years in the same ward, were selected in each of the 22 studied wards as key informants and facilitators in selecting focus group discussion participants. Gender consideration was assured in selecting AGRITEX officers to solicit a comprehensive package of gender-based perspectives from communities using the extension workers' fraternity. Preference was also given to those officers having served in the ward for over five years and whose area knowledge was rich enough to meet the objectives of the study.

In each ward, one (1) representative from the local traditional leadership was randomly chosen and interviewed to give additional insights on local adaptation barriers. Traditional leaders hold regular meetings with their subjects, the majority of whom are smallholder farmers; hence, they form aggregate constituencies of insights from the smallholder farmers' fraternity. Researcher observation exercises meant to verify what respondents stated were 
done in two ways. First, these were undertaken immediately after the FGDs, meaning that the researchers picked key points of adaptation challenges to observe based on what FGD participants stated. Second, transect walks to observe phenomena were also scheduled after observation points were picked from in-depth interviews done with key informants. The rationale was to corroborate all ground-proven allusions and perceptions from FGDs and exhaustive interviews.

To analyse the data, in-depth qualitative analysis was done to come up with a narrow set of climate change adaptation barriers. The data from focus group discussions and in-depth interviews were coded and indexed accordingly [22] to note patterns of what, who, and why farmers specifically blamed for their reduced adaptive capacity. The respondents stated different barriers in varied semantic dimensions that still portrayed specific categorical linkages. Since all the diverse responses on barriers could not be independently presented in the findings, thematic content analysis was used to compress the huge qualitative explanatory responses on climate change adaptation barriers, thus aligning the method with Ibrahim's [23] approach. Results were presented in summary using a narrative approach corroborated by selected citations from interviewees. While interviews were conducted in the locally spoken Shona language, the citations were translated and presented in English.

\section{Results}

\subsection{Barriers to Smallholder Farmers' Adaptive Practices}

Whilst this presentation focusses more on climate change adaptation barriers and their connectedness, our interview and discussion questions began with general topics and later focussed on barriers. The questions had to do with (i) confirmation of the respondent's awareness of the changing climate; (ii) whether farmers were making efforts to adapt to the changing climate; (iii) the specific factors that were regarded as barriers to the attainment of effective adaptation; and (iv) identification of some drivers of what smallholder farmers regarded as barriers to the climate change adaptation process. Since they are not the paper's key objectives, responses to the first two questions subtly appear in the findings that address question themes in (ii) and (iii). Despite the broad semantic dimensions provided by respondents, our findings were narrowed down to reflect the key categories that were implied by various respondents.

\subsubsection{Climatic Barrier}

The majority $(68 \%)$ of the 44 extension workers that were interviewed cited climatic barriers as the main constraint to adaptation. Of the total number of traditional leaders $(n=22)$ who were interviewed, most $(81.8 \%)$ of them also felt that climate was the most constraining factor. These were corroborated by views from several participants in FGDs that were held. The inconsistent climate scenario has made it hard for smallholder farmers to adapt to the ongoing change. The serious shortage of rainfall over recent years has become a major climatic barrier. There were striking exceptions in the cases of wards such as 21 (Ngorima A), 22 (Ngorima B), 23 (Ndima), and 10 (Chikukwa), where recurrent cases of excessive rainfall have increased over the years. Consequently, smallholder farmers lose out to waterlogging and crop rotting. We captured outstanding sentiments regarding the climate scenario by one elderly farmer at Ngorima B:

In the low veld, farmers suffer from serious droughts but here in the eastern highlands our challenges have mainly to do with too much rainfall. Mid-season droughts also occur but they are often short-lived. Once the rains start, we hardly work in our fields and the crops remain stunted. Those who plant early still face the challenges of their crops getting waterlogged and finally rotting.

In a contrasting scenario, farmers in low veld Wards 2, 3, 5, 8, and 20 often got stranded following their failure to plant due to acute water shortage. Such an unreliable rainfall pattern made it hard for rs to adapt. The obtained reports were in tandem with an Oxfam-UNDP [24] study in selected low veld wards, which similarly indicated that the 
district currently experiences the late onset of rainfall, mid-season dry spells, and early rainfall cessation.

\subsubsection{Financial Barriers}

In all the 22 wards studied, smallholder farmers acknowledged the need to adapt to climate change by reorienting their practices to suit the new conditions. However, financial challenges were massively noted as a stumbling block to climate change adaptation. Farmers and extension officers reported that the ongoing massive job losses, cash shortage in the country, and the recent technological shift from the usual use of hard currency to heavy reliance on direct money transfer methods such as the use of credit cards and electronic transactions have overstretched the flexibility of most farmers. Through the EcoCash payment facility, farmers can transfer money during purchase transactions. Unfortunately, many shop owners decline the use of money transfers in preference to hard cash in foreign currency form, especially the US dollar. The recent shift in technology has reportedly reduced smallholders' flexibility to obtain seed, fertilizers, and agrochemicals and to pay for many other farm utilities.

In wards such as Mhandarume-Mashowani (Ward 2) and Chikwakwa (Ward 19) with fish farming projects, an artificial supply of fish feeds was paralyzed due to lack of funds. This followed the withdrawal of direct involvement by the founding NGOs, World Vision and Karitas, respectively. Details of the projects' deterioration were sought from the four (4) interviewed extension workers who worked closely with the farmers on the projects. In Ward 19, the two extension officers both reported that as the cost of fish escalated, only three $(10.7 \%)$ of the 28 beneficiaries remained with the capacity to provide fish feeds, but on a fairly irregular basis. The statement of the challenges coincided with what FGD participants in the affected village stated as the reason for the decline of the project. This financial challenge crippled the project because the few $(10.7 \%)$ involved beneficiaries claimed exaggerated shares during the devolution of proceeds from the scheme, a development that further crippled the initiative.

\subsubsection{Ill-Defined Property Rights}

Legal problems were reported in all 22 wards in the district, but these emanated from different scenarios. In wards where there were community irrigation projects $(2$, $3,4,5,6,8,9,17,18,19$ and 20), legal problems were related to water management dynamics. Beneficiaries of irrigation projects had set up water use rules and regulations in Ward 6 (Shinja), Ward 8 (Nyanyadzi), Ward 9 (Zimunda), Ward 4 (Nhedziwa), Ward 2 (Mhandarume), and Ward 18 (Mhakwe). Unfortunately, these have remained non-legally binding and were easily flouted by beneficiaries and other members of the community. This scenario caused serious operational challenges in terms of regulation and protection of the water supply intended for beneficiary members of the irrigation schemes. A total of $10(91 \%)$ of the 11 interviewed extension workers in the affected wards confirmed the complexity of the water management situation. We captured the sentiments from one extension officer in Ward 8 (Nyanyadzi) as follows:

There are serious legal implications for the water situation in this ward. Before independence, the police used to conduct raids upstream of the Nyanyadzi river to apprehend illegal water users. Now the situation is different. Many people illegally abstract water even from major project canals without being deterred. Those who have canals do not have water abstraction licenses so there is no strong legal basis for them to fight back in the event of their water being interfered with.

They believed they had a right to utilise water as long as canals and pipes pass nearby. They claimed that they had the right to use water, arguing that bypassing canals and pipes interfered with portions of their homesteads and crop fields.

Attempts by IMC members to counteract the acts of irrigation water piracy have often spilt into conflicts that even the Zimbabwe Republic Police (ZRP) officials and traditional authorities have failed to contain. In their pursuit of the matter, law enforcement agents' 
efforts usually proved to be futile because such cases would take a swing into community members' political affiliations, creating a legal situation that many admitted was too complicated to handle.

We observed a differing nature of legal challenges to those smallholder farmers in the eastern highlands part of the district in Wards 1 (Cashel), 7 (Bumba), 11 (Martin), 12 (Charleswood), 13 (Charter), 14 (Nyahode), and 16 (Gwindingwi), where many smallholder farmers were beneficiaries of the fast-track land reform programme. Here, views from FGD sessions reflected farmer scepticism, which was linked to their lack of legal proof of land ownership in the form of farm title deeds.

\subsubsection{Infrastructural Barriers}

Infrastructural challenges were recorded, but they also differed widely depending on the geographical background of the ward. Several irrigation pipes were installed alongside major rivers in wards with steep terrain, such as Biriiri (Ward 17), Mhakwe (Ward 18), Chikwakwa (Ward 19), Chikukwa (Ward 10), Ndima (Ward 23), Ngorima A (Ward 21) and Ngorima B (Ward 22), and most smallholder farmers have adapted to climate change by abstracting water from mountain springs and rivers for irrigation and domestic use. Unfortunately, several pipes remained highly exposed with no trenches dug to cover them, such that the infrastructure suffered from high vulnerability to vandalism. The infrastructure was also exposed to extreme weather. Figure 2 shows the exposed water pipes that were put up following the Cyclone Idai flood disaster in the Chinamira Village (Ward 17).

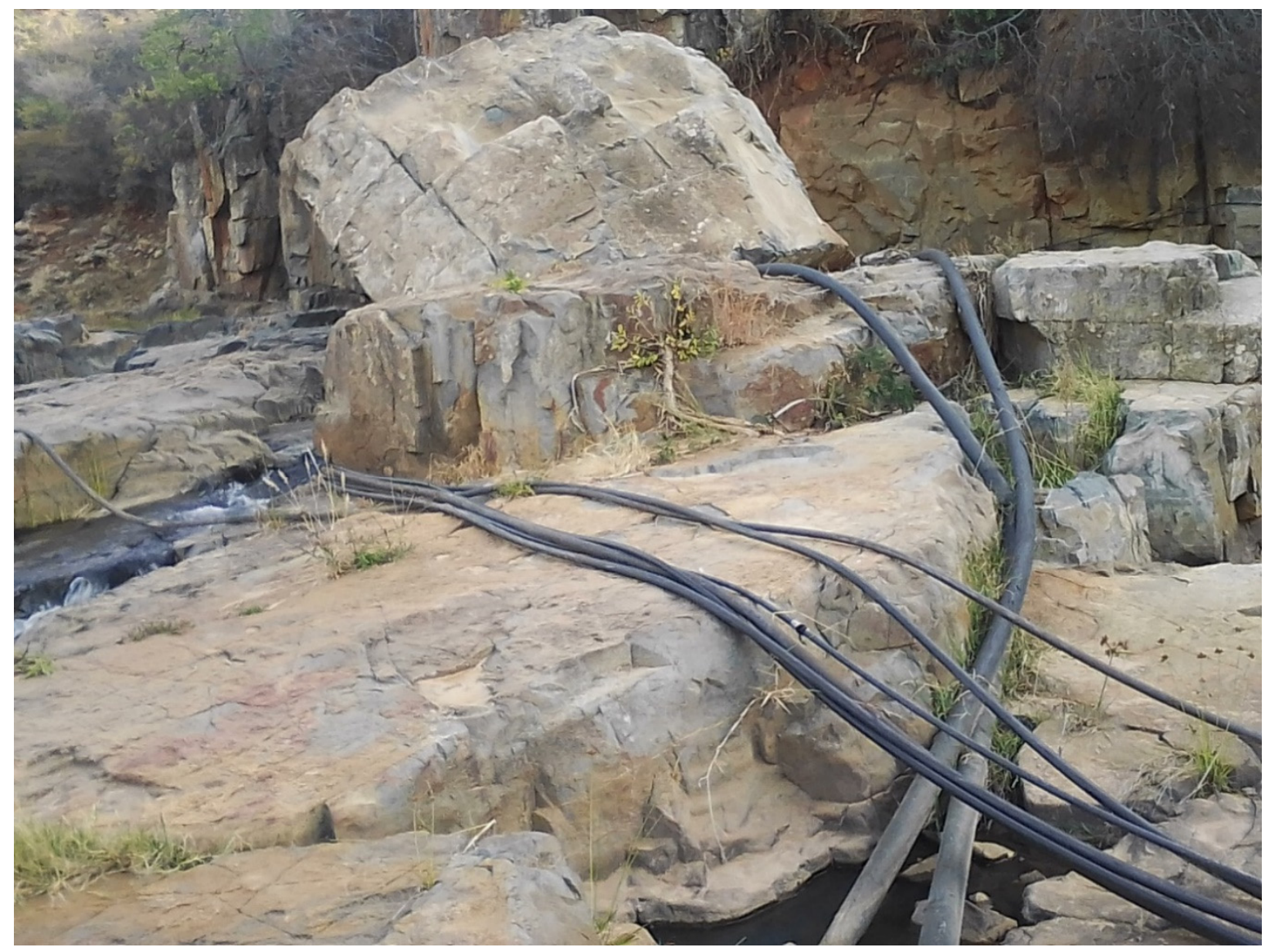

Figure 2. Highly exposed water harnessing pipes in the Chinamira Village (Ward 17).

In wards with gentle terrains like Chakohwa (Ward 3), Nhedziwa (Ward 4), and Nyanyadzi (Ward 8), respondents revealed different sentiments regarding infrastructural 
challenges. The three extension officers in the wards lamented the vulnerable state of farmers' open canals, which were used to abstract water to plots. They concurred in asserting that the dry weather conditions induce excessive water loss to high evaporation and seepage. In Gudyanga (Ward 20) participants in the two FGDs complained of a lack of rain harvesting dams.

The road infrastructure barrier was reported in all remote parts of the 22 wards in the district. There was, however, a difference in the emphasis of the challenge. Wards situated in the low-lying areas with gentle terrains $(2,3,5,8,20)$ did not consider road infrastructure as seriously as it was considered in administrative wards characterised by rugged terrain. In Wards 21 (Ngorima A), 22 (Ngorima B), and 23 (Ndima), smallholder farmers bemoaned their poor connectivity to the urban areas of Chipinge and Mutare, despite the abundance of fruits in the areas. Figure 3 shows a broken bridge along the road that links Nyamusundu (Ward 17) with the Chimanimani-Mutare highway. Ever since the Cyclone Idai flood destroyed the bridge in 2019, it has not yet been repaired. Such scenes are common on many roads in remote settings around the district.

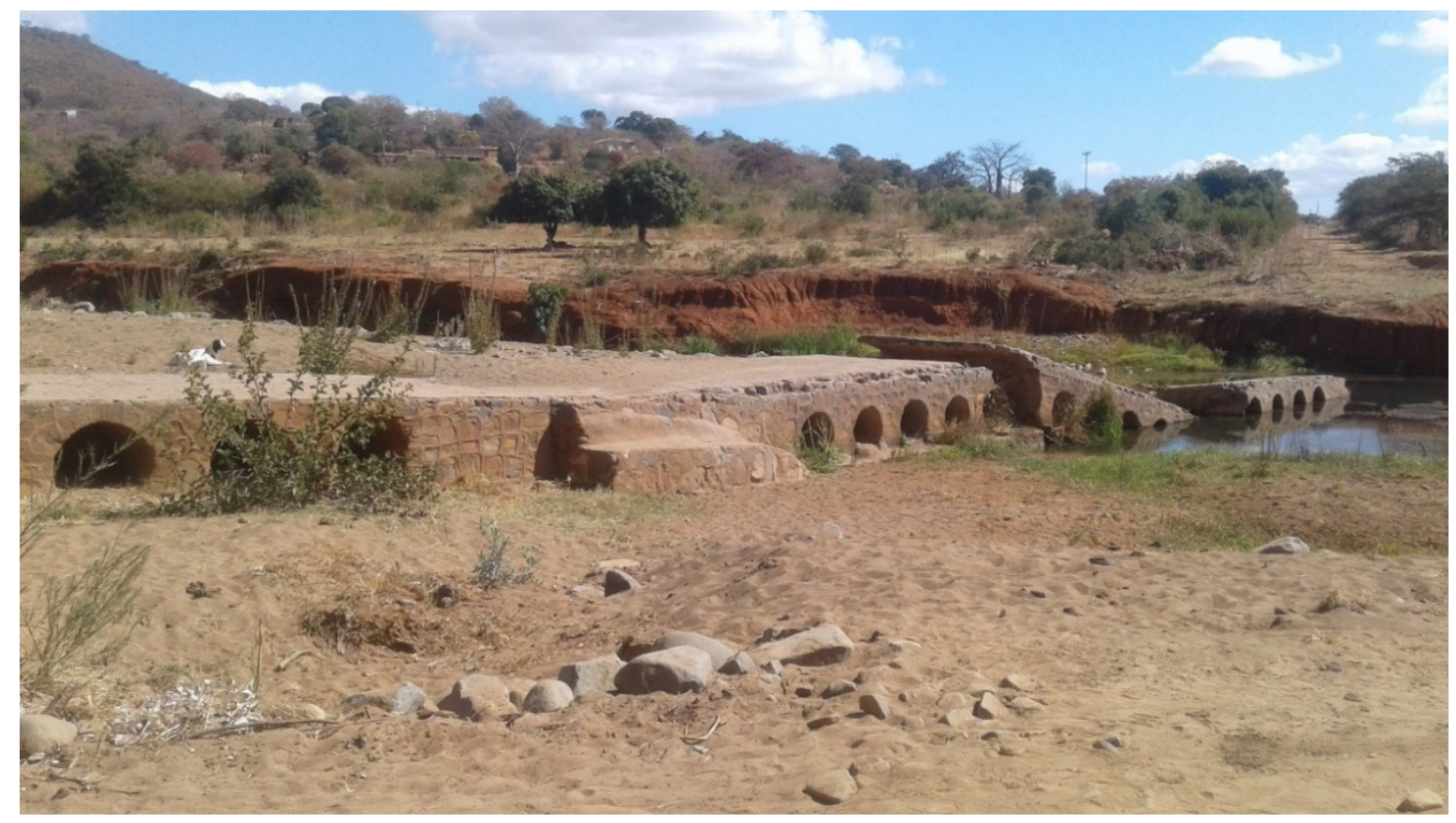

Figure 3. An idle bridge destroyed by the Cyclone Idai flood in March 2019.

Farmers also expressed acute concerns over the lack of suitable storage infrastructure to preserve their agricultural inputs and produce in a safe state. Inputs such as fertilizer, chemicals, and seeds often got wasted due to a lack of proper storage facilities. In some instances, farmers stored their produce on rooftops because of a lack of appropriate storage infrastructure. In many dry areas, termites were identified as the main threat to store barns. In a contrasting scenario, Wards 10 (Chikukwa), 21 (Ngorima A), 22 (Ngorima B), and 23 (Ndima) reported incidents of crop rotting during times of excessive rainfall. During transect walks it was common to notice within communities that farmers stored their harvest on rooftops before trashing it. The unfortunate part of such a practice was that the product remained exposed to weather adversity and general insecurity.

\subsubsection{Constrained Water Resources}

All the 44 extension officers interviewed in the 22 wards underscored the need for farmers to switch from dependency on rain-fed farming to the adoption of irrigation. However, the barrier to this form of adaptation has been the inadequacy of water. Water constraints manifested in a wide range of ways. In the Nyanyadzi River catchment, the 
Nyanyadzi Irrigation scheme reflected the most serious level of constraining, since most of its upper waters have recently been harnessed by emerging irrigation initiatives. The scheme has four sections (section A-D), each with over 60 smallholder plots that thrive on irrigation water from the Nyanyadzi River. The new schemes that were opened up in Wards 6 (Shinja), 9 (Zimunda), and 18 (Mhakwe) have added an extra strain on the supply of water to downstream farmers. A similar water shortage scenario was reported along the Mvumvumvu River catchment, which comprises five huge irrigation schemes. These are Cashel (Ward 1), Mutambara (Ward 4), Gonzoni (Ward 4), Mhandarume-Mashowani (Ward 2) and Chakohwa (Ward 3).

We interrogated the respondents in the affected wards and established that waterrelated conflicts prevailed quite often, signifying the extent of the challenge. Traditional leaders in the affected areas reported an average of five conflicts each month, some of which ended up in courts, as one village head in Nyanhanda Village, Nyanyadzi (Ward 8), narrated:

This small canal is our only source of irrigation water supply for all the huge sections from $A$ to $D$. We are tired of quelling water-related conflicts. Today it is about one farmer blocking another farmer's canal, tomorrow another farmer withdraws another farmer's water abstraction syphons and so on. Our water supply is so constrained that we handle about five cases every month.

In some extreme cases, households and community factions have had conflicts to protect their interests, leading to serious casualties. It has increasingly become a problem to regulate the amount of water that individual beneficiaries get.

\subsubsection{Inefficient Bureaucracy}

Reports of lack of coordination and timeous response by some support institutions have created serious setbacks to smallholder farmers' adaptive capacity. We established bureaucratic inefficiency in $45(82 \%)$ out of the 51 FGDs administered across the 22 wards. In administrative Wards $1,7,11,12,13,14$, and 16, where smallholder farm settlement had profoundly occurred, there were repeated complaints regarding the delay in the release of farming inputs such as seed and fertilizer. Farmers who received delayed supplies of government subsidies ended up selling their domestic valuables to purchase inputs; hence, they lamented the extended bureaucratic procedures being followed before inputs were delivered to them. The delays were confirmed by nine (64\%) of the 14 extension workers interviewed in the affected wards. One senior extension officer reiterated that bureaucratic delays were linked to the lengthy procedure characterizing the movement of inputs and related paperwork, the process of which involved several signatories.

Many smallholder farmers have become increasingly dependent on government and other institutions that provide inputs to cushion farmers against their increased financial incapacitation. In some instances, the delivered seed did not suit the local area conditions, meaning that the responsible technical authorities did not give thorough attention to their work. At the same time, those responsible for land redistribution under the government land reform programme were also reportedly not fully coordinating with the Environmental Management Agency department to ensure that a more sustainable approach to the process was effected.

Acts of bureaucratic inefficiency were also reflected in the traditional leadership fraternity. In some middle (Ward 9, 18, and 19) and low veld (Wards 2, 3, and 5) wards, traditional leaders reportedly derailed the release of land targeted for new irrigation initiatives. Traditional leaders themselves happened to own the biggest idle tracts of land in each of the wards. FGD reports in the affected wards showed that the leadership practised stated traditional procedures that were hard to fulfil. In some extreme instances, Chimanimani Rural District Council officials had to intervene, leading to some landowners non-consensually surrendering their land for the development of community irrigation projects. Such bureaucratic complexities formed a stumbling block to the effective building of climate resilience. 


\subsubsection{Free Rider Problems}

Besides external forces inhibiting the initiatives put in place by smallholder farmers, the farmers themselves also demonstrated their behavioural weaknesses, which acted as barriers to adaptation. We gained insight from extension workers who assisted farmers with low-cost climate change adaptation knowledge and skills. The majority (86\%) of extension officers and traditional leaders who were interviewed confirmed the failure by several smallholder farmers to implement some of the conservation measures that they were taught. Farmers in administrative wards that experienced rapid moisture loss after rains (Wards 2, 3, 4, 5, 6, 7, 8, 9, 17, 18, 19 and 20) were taught conservation farming techniques such as digging pits to plant crops. The pits harvest water and retain moisture for extended periods after the rains. Unfortunately, the practice was dropped in many wards as farmers found it labour-intensive to prepare the pits.

The majority $(68 \%)$ of the interviewed traditional leaders also confirmed the lack of motivation to support sustainability projects in their subjects, which they said manifested in diverse ways. In administrative Wards 9, 17, 18, and 19, smallholders reportedly declined repeated calls to employ low-cost and community-based road maintenance to facilitate the movement of people and goods. In Ward 20, a TSURO Trust-funded livestock water project stalled after villagers failed to harmoniously coordinate its operations. In the dry and sparsely vegetated Wards $2,3,4$, and 5 , tree nursery projects failed to thrive following the affected community's failure to regularly water the nursery. The local traditional leadership and extension workers stated that smallholder farmers declined to water the tree nursery despite having been trained in how to nurture the trees.

In administrative Wards 4, 8, and 18, there were reports of unscrupulous irrigation project beneficiaries who disregarded irrigation water supply schedules. Because of the acute shortage of water, many studied irrigation schemes in the district currently operate under locally agreed water supply timetables. Water supply is rationed for all farmers to at least benefit. Despite the schedules being in place, some individuals still contravened the regulation on irrigation schedules, leaving other beneficiaries stranded.

\subsubsection{Gender-Based Barriers}

Throughout all wards visited, women outnumbered their male counterparts in focus group discussions except in Wards 11, 12, and 14, where males dominated at four (67\%) out of the six FGDs administered. Here, the majority of eligible participants were male household heads. We interrogated the six extension workers on this disparity. Their responses pointed to the fact that many households in the area were male-headed and characteristic of setups in which the families had not yet completely relocated from drier areas such as Mhakwe, Biriiri, Nyanyadzi, and Gudyanga. Researcher observation visits helped to confirm that several pieces of land were still under clearance, hence, more males than females resided there doing the work. The adaptive challenge that reportedly emerged from this gender disparity was that males dominated the decision-making process at most farms.

Unlike in these unique three wards $(11,12$, and 14$)$, females were noted to participate more in smallholder farming activities than males. Nonetheless, some climate change adaptation barriers manifested in the sense that male household heads reportedly held the responsibility to purchase seed and other inputs, leaving the task of planting and tendering of crops to women and children whilst they engaged in off-farm activities. As such, female respondents widely bemoaned their lack of equal involvement in choosing the practices and specifying which inputs to use for each season.

\subsubsection{Generational Change}

Smallholder farming thrives chiefly on family labour availability [24]. Sentiments from focus group discussions indicated that the district's 22 wards were faced with a severe labour challenge due to the dwindling number of youths involved in smallholder farming. The severity of the challenge varied across many wards. In resettlement wards $(1,7,11,12$, 
13,14 , and 16), households lamented the lack of support from young members of the family who declined to work in the remote resettlement plots. In low veld wards, especially 2, 3, 4, 5,8 and 20, a labour shortage impacted negatively on productivity in the irrigation plots. Wards 21, 22, and 23 are close to the country's border with Mozambique. The massive emigration of the youths to Mozambique and South Africa has led to a serious family labour shortage. An elderly traditional leader interviewed in Ward 7 related that the youths of today no longer desire farming but urban-related activities. We captured sentiments from one FGD participant who had this to say:

Climate change has no reverse. Rains will never come as before and our parents and grandparents should understand that. Instead of losing out to drought on an annual basis, I suggest that we sell our plot near Nhedziwa business centre to those people seeking residential stands. In return, it seems wise for us to invest in other family business opportunities that are outside crop farming particularly that which depends on natural rainfall.

Similar sentiments were shared by the 44 interviewed extension officers in the district. the majority $(68 \%)$ of them pointed out that they seldom engaged with youths in their community intervention programmes. Field visits by researchers showed that there were several youths in the district that spent more time in business centres engaging in urbanbased livelihoods while their parents were out in the fields. In their perception, youths who participated in mixed group FGDs argued that they better understood climate change than their parents such that focusing on arable farming under the circumstances remained impracticable.

\subsubsection{Health Challenges}

The prevalence of climate change itself was reported to have caused a lot of health havoc for smallholder farmers. In hot weather conditions were reported to be exacerbating the state of health ailments for many people, particularly in the low veld areas covering wards such as Wengezi, Nyanyadzi, and Gudyanga. The continued spring temperature was reported to be a negative development to those already with health ailments such as migraine headaches and asthma. Under such circumstances, it became hard for farmers to spend long hours working in the fields. One senior extension officer in Nyanyadzi expressed that most elderly people had health problems due to complex weather conditions that come with climate change. Going further, he alluded that the smallholder farming sector was shrinking because older people were forced to go into the fields and work over short hours since the youths continue to shun the sector in preference for urban-based engagements. Another elderly couple in Nechitima (Ward 3) explained:

Many people utilised a diverse range of herbs before climate change took a toll on the ecological environment. Forests used to provide medical and spiritual services to locals, but, of late, people suffer from various health complications due to the extinction of some valuable herbs in the wake of climate change.

The Coronavirus disease (COVID-19) lockdown has also added to the long suffering of the smallholder communities due to its related health uncertainties. The already lessstocked farmers suffer from a lack of basic supplies, including agricultural inputs, due to the COVID-19 lockdown. In many cooperative projects, smallholder farmers are faced with a health scare, hence, they are restricted from gathering and working together as they used to do before. This has impacted negatively on their culture of sharing ideas and resources. As the COVID-19 pandemic has continued to spread, smallholder production has reportedly slumped as well in many community settings.

\subsection{Barriers to Climate Change in Chimanimani District: An Analytical Perspective}

In this section (3.2), we used an emic approach to extend the concept of climate change adaptation barriers based on findings from smallholder farmer experiences in the Chimanimani District. Our conceptualization of adaptation barriers was premised on the 
view that these are, of course, multiple but generally intertwined to form a complicated system of barriers, as opposed to stand-alone barrier entities.

To understand the interdependencies of barriers is central to explaining their occurrence, persistence, and resolution [2]. Besides, it is viewed that in climate change and vulnerability science, "there is no single universally accepted way of formulating the linkages between human and natural systems" [25]. Therefore, we aggregated qualitative views from FGDs, observations, and in-depth interviews and presented the various adaptation barriers in their connected sense. Using the systems thinking approach, the connectedness of barrier links was composed using Vensim PLE 7.3 Software and is illustrated in Figure 4.

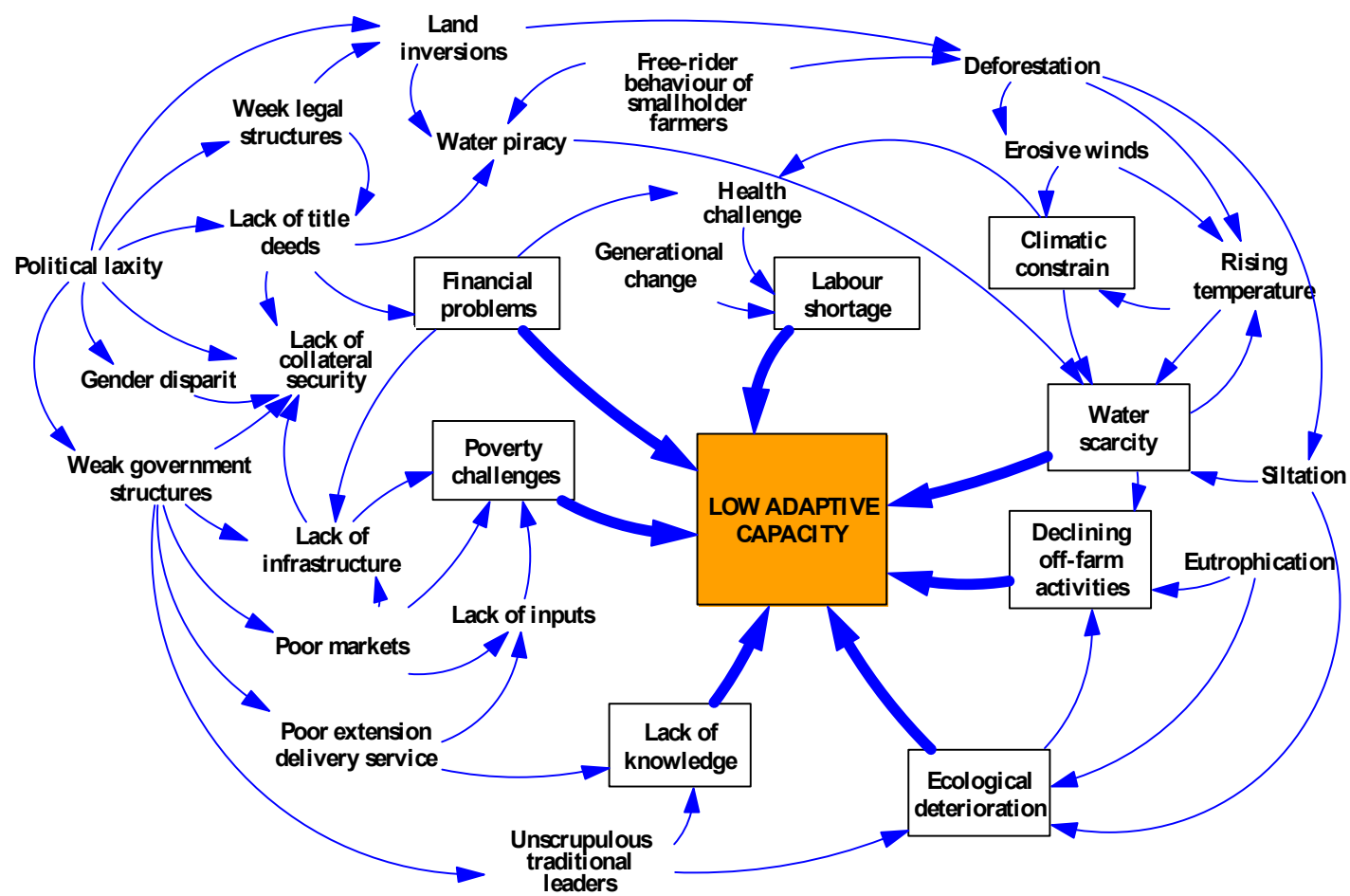

Figure 4. Causal loop diagram showing the connectivity of climate change adaptation barriers in Chimanimani District.

Integrating the barriers was necessary because [2] argued that intervention policies aimed at overcoming adaptation barriers may prove to be ineffective if causal interdependencies are disregarded. Policy makers may struggle with one challenge, not realising the intricate sub-challenges linked to the more vivid one. In this diagram, we deliberately differed the thickness of connecting lines in a bid to highlight the varying emphases given by the respondents. The thick lines represent the aggregates of factors that different respondents ranked highest in hindering smallholder farmers' adaptive capacity. The thin lines represent weaker, but still important, connections between different barriers [11].

As farmers struggle with one challenge, it translates into a whole new form of challenge, altogether forming a complex network of barriers that draw back the efforts put in place by the farmers themselves. This concurred with Sherwood [15] who, in support of cyclical rather than the linear cause-effect relationships, asserted that altering part of a system component can unfavourably affect other parts of the system. As reported by the farmers themselves, lack of financial capital led to choices and practices that were relatively cheap to them. The latter included felling thorn branches to fence crop fields, which in turn translated to increased deforestation and more ecological challenges. Failure to afford costly but sustainable water abstraction methods led to streambank cultivation as farmers aimed to cut water abstraction costs. The feedback was related to excessive siltation and, ultimately, water pollution and acute shortage. Also, the lack of access to loans by many farmers was reportedly a result of their general lack of collateral security. 
The latter was entangled in the government's failure to expedite the provision of land ownership accreditation to farmers following the countrywide ad hoc land occupations. The failure by the government to expedite the issuing of land title deeds to farmers meant the latter were unable to access the much-needed loans from banks.

Farmers complained of a lack of adequate information on how best to utilise the inputs that they received from various supply agents. Reference was widely made to the laxity by AGRITEX field officers when giving appropriate and adequate information to farmers. When probed for clarity on this matter, the AGRITEX officers in turn explicitly alluded that institutional capacity was constrained by the poor remuneration that they got from the government. In return, the little effort put in place by the government and non-governmental development agencies was allegedly misused due to the ill-focused behaviour of many smallholder farmers.

Government authorities have reportedly created legislative frameworks that permit a wide range of lax forms. The weak government policies permitted smallholder farmers to develop equally inappropriate behavioural traits that worked against environmental justice. Lack of title deeds means farmers are not fully entitled to the land that they use. When farmers lack full ownership of their land, they use it without full responsibility for its damage because, according to one extension officer, farmers can easily be moved out of the land by government officials to pave the way for new owners with a stronger legal entitlement to the land. Again, lack of collateral security means farmers hardly have access to bank loans, which they must use to buy essential farm inputs, thus extending the poverty chain.

According to the FAO [24], limited access to markets increases smallholder farmers' vulnerability to climate change shocks and impedes economic opportunities that would crop up if trading opportunities were easily available. Accordingly, the poor market situation faced by smallholder farmers in Chimanimani leads to poor financial capacitation as farmers fail to trade and raise their income status. The result is a failure by the farmers to afford to buy farm necessities. With this experience at hand, farmers adapt poorly to climate change. Smallholder farmers who were further probed on lack of market knowledge blamed it on inadequate information supplied by extension workers. In their response, the extension workers also indicated that they could not deliver effectively against the backdrop of poor remuneration.

\section{Discussion}

Whilst a continued change in climate in Southern Africa is still debated [25-27], reflections from FGDs, key informants, and observation data regarding rainfall decline in this study did not deviate from what the previous studies reflected. According to [28], the downscaled future climate change scenarios for the Save River basin in southeast Zimbabwe for the periods 2046-2065 and 2081-2100 predict a temperature increase of between $1.5^{\circ} \mathrm{C}$ and $3.5^{\circ} \mathrm{C}$ across the basin, where the greater part of the district lies in the lower belt. This corroborates the increase in temperature alluded to by many AGRITEX officers and smallholder farmers in the Chimanimani District. Our study area, Chimanimani District, is home to all five agro-ecological regions in the country that have undergone reorientation due to climate change $[28,29]$.

The fact that rural people of Chimanimani District thrive largely on agrarian livelihoods is common throughout rural communities, particularly in the developing world. Communities that rely on the agrarian economy have faced climatic hardships and therefore fought to build resilience to the related stressors since time immemorial [30]. However, climate change has continued to bring more extreme weather scenarios beyond the farmers' ability to understand and adjust to accordingly. Gitay et al. [31], in this case, argued for the mobilization of institutional support from state universities and civil society organizations to assist farmers with climate-smart strategies. This is the component that many smallholder farmers are lacking, hence, their increased failure to adapt to climate change. Otherwise, effective agriculture production requires the proactive provision of 
relevant inputs at a timeous moment $[7,32]$ when there are government institutions directly responsible for all these mandates.

Zimbabwe is a signatory to quite a number of international commitments on adaptation. Several synergies do exist in these commitments and in the ultimate national policies, all of which can be harnessed to benefit development in Chimanimani and Zimbabwe in general. The country signed and ratified the United Nations Convention on Biodiversity (UNCBD) in 1994. It became the first country in Southern Africa to effectively complete its Biodiversity Strategy and Action Plan (BSAP) [33]. Zimbabwe has also submitted its Intended Nationally Determined Contribution (INDC) to the United Nations Framework Convention on Climate Change (UNFCCC). With Zimbabwe's economic sectors being highly vulnerable to climatic change, these commitments were meant to affirm the country's position on building resilience through climate-smart developmental initiatives. Nevertheless, the key production sectors, particularly agriculture, forestry, wildlife, and aquatic life, are deteriorating due to lack of effective management and cross-sectoral engagement. It was equally echoed by Nyiwul [7] that such an unfavourable institutional and policy environment in the majority of African countries does hinder prospects of funding, capacity enhancement, and technological innovation.

What is lacking in the Chimanimani District is the earnest implementation of statutory tools and coordinated institutional approaches that ensure sustainable practices within smallholder farming communities. Institutional slackness has been noted in other studies $[10,30]$, and this includes traditional institutions [34,35]. This agrees with [36], who noted that a collection of ministries dealing with the "environment" (environment, water, and agriculture) and those having to do with "economy" (economic planning, finance, and small and medium enterprises) have contending claims for priority in engaging with climate-related issues. Likewise, grassroots institutions (formal and informal) mandated to work with smallholder farmers are at times reflective of the slack governance policies instituted at the highest level.

Smallholder farmers, extension workers, and traditional leaders in Chimanimani District have widely reported financial shortages as a key barrier to effective adaptation. Although they covered some selected wards, [37] also noted financial challenges prevailing in the district. Financial challenges were also recorded in Muzarabani District in Zimbabwe [1], where smallholder farm production failed to reach anticipated levels. Several institutional frameworks and financial programs are available to cushion smallholder farmers against climate change stressors in Zimbabwe. However, what lacks in many instances is the ability of concerned financial institutions and governing authorities to institute them in an honestly planned manner that addresses climate change adaptation needs.

In the climate change adaptation mainstream, trading off household valuables, like what smallholder farmers in Chimanimani do, draws back the adaptive capacity enhancement objective. The intervention by government and financial institutions through capital injection is now mandatory because climate change is now known to be an economic and financial risk [36]. Otherwise, when the physical environment continues to constrain and reduce farmers' ability to produce reliable outputs from their fragile land, the farmers resort to selling their livelihood assets such as cattle, goats, chickens, and household utensils as an off-farm strategy to deal with food shortages [37,38]. In other studies, [1,39], smallholder farmers reportedly knew the long-term negative consequences of trading off their livestock but they still did so due to their lack of alternative livelihood options.

Smallholder farmers themselves are missing out on several expectations, as well.

Water management failure noticed in Chimanimani (and prevailing in Zimbabwe, in general) is a result of a complex web of broader governance slip-ups cascading into institutional laxity and farmer ill-behaviour. The 1998 National Water Act paved the way for power decentralization through the creation of Catchment Councils (CCs) and SubCatchment Councils (SCCs) as the main institutions to manage the efficient use of water. This paper argues that some unscrupulous members who flout the gazetted water-sharing schedules in Chimanimani District are simply exploiting the loopholes that currently 
characterise the national and local water management systems. This is not new because literature states that in the politics of communal water governance, there is a traditional belief that water has always been a sacrosanct and free resource whose exploitation should be limitless [40]. In the wake of climate change, the latter is a misconception and, therefore, a highly archaic perception.

The weaknesses of traditional authorities cascade into the local scale to barricade anticipated climate resilience-building initiatives within the smallholder farming sector. It is acknowledged that traditional leadership is "an institution that fulfils a governance gap where conventional democracy has not fully extended itself" [41]. Furthermore, local traditional setups have, for quite a long time, served to harmonize the sharing of resources such as water and land [40]. Although traditional authorities were found to be problematic in post-independence Africa [41-43], there is room for them to bring harmony within communities [5] if they deliver their mandate with jurisprudence.

Whilst some climate change adaptation initiatives have proved to be too expensive for smallholder farmers in Chimanimani, indigenous knowledge can be a useful tool in the adaptation discourse. To date, the literature is awash with allusions to the need to add indigenous climate knowledge to existing conventional climate knowledge [44,45]. Even though indigenous knowledge is fast becoming eroded by the advent of conventional science $[45,46]$, it can still be revitalized and mainstreamed into climate change adaptation together with conventional climate science. To address this gap will require a revised governance approach at both national and local government levels buttressed by local area support from smallholder farmer communities.

The Chimanimani study raised other critical issues about gender discrepancy unfolding in many resettlement areas. From the studies done in Ghana, Uganda, and Bangladesh, it was also confirmed that women were found to be less adaptive due to male domination in the reception of information and extension services, while higher labour loads remained for women [47]. Surprisingly, the United Nation's Sustainable Development Goals (SDGs) support gender consideration through Goal Number 5. Thus, to achieve gender fairness means that countries have to address gender-based decision-making in smallholder farming [47-50] since women play a critical participation role in the sector.

\section{Conclusions and Recommendations}

The study explored barriers to climate change adaptation as encountered by smallholder farmers in Chimanimani District, Zimbabwe. Smallholder farmers in the district suffer from a host of climate change adaptation barriers. These include climate stress, finance, legal structures, infrastructural challenges, constrained water resources, inefficient bureaucracy, behavioural flaws, gender-based constraints, generational change, and health challenges. Our findings revealed that barriers may be similarly identified per se but they manifest distinctively according to the localised geographical conditions that characterise each ward in the district. Furthermore, the study showed that climate change adaptation barriers are intricately connected to form a complex network that deters smallholder farmers' ability to build effective climate change resilience.

The study, therefore recommends that:

- Communities are further educated for them to understand that they can build more climate change resilience beginning with the little resources available to them.

- Local traditional authorities can also harmonize the sharing of land and water resources amid climate change adaptation initiatives if they remain transparent and honest to their subjects through their practices.

- An all-inclusive and nonlinear approach is required in addressing barriers to climate change since they affect smallholder farmers in an interconnected manner.

- Institutions working with smallholder farmers should be well-coordinated in their intervention to fight common climate change adaptation challenges. 
Author Contributions: H.M. conducted two interviews, analyzed the full data set, and drafted the paper. W.C. designed and led the field research, supervised the analysis of data, provided useful editorial suggestions during the writing of the paper, and supported the writing and submission of the paper. All authors have read and agreed to the published version of the manuscript.

Funding: This research received no external funding.

Institutional Review Board Statement: Not applicable.

Informed Consent Statement: Not applicable.

Data Availability Statement: Data are available on request due to restrictions as PhD Thesis is held by university for three years. The data presented in this study are available on request from the corresponding author. The data are not publicly available due to institutional regulations to hold the data for three years.

Acknowledgments: This research formed part of the baseline research activities led by Wisemen Chingombe from 2016 to 2020. Happwell Musarandega supported this research whilst studying for his $\mathrm{PhD}$ dissertation, Understanding climate change risk and vulnerability: Unpacking adaptation strategies for small scale holder farmers in Chimanimani District, Zimbabwe. The University of Fort Hare. A copy of the full research report is available from Happwell Musarandega, email: hmusarandega@gmail.com.

Conflicts of Interest: The authors declare no conflict of interest.

\section{References}

1. Mavhura, E. Building resilience to food insecurity in rural communities: Evidence from traditional institutions in Zimbabwe. Jàmbá J. Dis. Ris. Stud. 2017, 9, 453. [CrossRef] [PubMed]

2. $\quad$ Eisenack, K.; Moser, S.C.; Hoffmann, E.; Klein, R.J.T.; Christoph, O.C.; Pechan, A.; Rotter, M.; Termeer, C.J.M. Explaining and overcoming barriers to climate change adaptation. Nat. Clim. Chang. 2014, 4, 867-872. [CrossRef]

3. IPCC. Summary for policymakers. In Climate Change 2014: Impacts, Adaptation, and Vulnerability. Summaries, Frequently Asked Questions, and Cross-Chapter Boxes; A Contribution of Working Group II to the Fifth Assessment Report of the Intergovernmental Panel on Climate Change; World Meteorological Organization: Geneva, Switzerland, 2014.

4. Otitoju, M.A.; Enete, A. Climate change adaptation: Uncovering constraints to the use of adaptation strategies among food crop farmers in South-west, Nigeria using principal component analysis (PCA). Cogent Food. Agric. 2016, 2, 1178692. [CrossRef]

5. Barnett, J.; Evans, C.; Gross, A.S.; Kiem, R.T.; Kingsford, J.P.; Palutikof, C.M.; Pickering, S.G. From barriers to limits to climate change adaptation: Path dependency and the speed of change. Ecol. Soc. 2015, 20, 5. [CrossRef]

6. Productivity Commission. Barriers to Effective Climate Change Adaptation: Report No. 59; Final Inquiry Report; Productivity Commission: Canberra, Australia, 2012.

7. Nyiwul, L.M. Climate change mitigation and adaptation in Africa: Strategies, synergies, and constraints. In Climate Change and Global Development. Contributions to Economics; Sequeira, T., Reis, L., Eds.; Springer: Cham, Switzerland, 2019 ; pp. $219-241$. [CrossRef]

8. Antwi-Agyei, P.; Dougill, A.J.; Stringer, L.C. Barriers to climate change adaptation: Evidence from northeast Ghana in the context of a systematic literature review. Clim. Dev. 2015, 7, 297-309. [CrossRef]

9. Doughty-Grajales, M. Identifying Institutional Factors that are Barriers to Climate Change Adaptation in Vietnam. Master's Thesis, Uppsala University, Hanoi, Vietnam, December 2013.

10. Biesbroek, G.R. Challenging Barriers in the Governance of Climate Change Adaptation. Ph.D. Thesis, Wageningen University, Wageningen, NL, USA, September 2014.

11. Arnold, R.D.; Wade, J.P.; Arnold, R.D.; Wade, J.P. A Definition of Systems Thinking: A Systems Approach. In Procedia Computer Science, Proceedings of the 2015 Conference on Systems Engineering Research, Hoboken, NJ, USA, 17-19 March 2015; Elsevier: Amsterdam, The Netherlands, 2015.

12. Shackleton, S.; Ziervogel, G.; Sallu, S.M. Why is socially-just climate change adaptation in sub-Saharan Africa so challenging? A review of barriers identified in empirical cases. Wiley Interdisciplinary Reviews. Clim. Chang. 2015, 6, 321-344.

13. Brown, H.C.P.; Nkem, J.N.; Sonwa, D.J.; Bele, Y. Institutional adaptive capacity and climate change response in the Congo Basin forests of Cameroon. Mitig. Adapt. Strateg. Glob. Chang. 2010, 15, 263-282. [CrossRef]

14. ZIMSTAT. Zimbabwe Population Census 2012; ZIMSTAT: Harare, Zimbabwe, 2012.

15. Sherwood, D. Seeing the Forest for the Trees: A Manager's Guide to Applying Systems Thinking; Nicholas Brealey: London, UK, 2002.

16. ZIMSTATS. Zimbabwe Population Census Report 2016; ZIMSTAT: Harare, Zimbabwe, 2016.

17. Government of Zimbabwe (GoZ). Zimbabwe's National Climate Change Response Strategy; Government of Zimbabwe: Harare, Zimbabwe, 2016.

18. Onwuegbuzie, A.J.; Collins, K.M. A Typology of Mixed Methods Sampling Designs in Social Science Research. Qual. Rep. 2007, $12,281-316$. 
19. Robinson, G.M.; Bardsley, D.K.; Raymond, C.M.; Underwood, T.; Moskwa, E.; Weber, D.; Waschl, N.; Bardsley, A.M. Adapting to Climate Change: Lessons from Farmers and Peri-Urban Fringe Residents in South Australia. Environments 2018, 5, 40. [CrossRef]

20. Walliman, S. Research Methods: The Basics; Routledge: New York, NY, USA, 2011; pp. 73-78.

21. Krippendorff, K. Content Analysis: An Introduction to Its Methodology; Sage Publications, Inc.: Thousand Oaks, CA, USA, 2004.

22. Jost, C.; Kyazze, F.; Naab, J.; Neelormi, S.; Kinyangi, J.; Zougmore, R.; Aggarwal, P.; Bhatta, G.; Chaudhury, M.; Tapio-Bistrom, M.L.; et al. Understanding gender dimensions of agriculture and climate change in smallholder farming communities, Climate and Development. Clim. Dev. 2015, 8, 133-144. [CrossRef]

23. Ibrahim, A.M. Thematic analysis: A critical review of its process and evaluation. West East J. Soc. Sci. $2012,1,39-47$.

24. Oxfam-UNDP. Scaling up Adaptation in Zimbabwe, with a Focus on Rural Livelihoods Project. Profile of the Odzi Sub-Catchment in Chimanimani District; Technical Report; OXFAM: Harare, Zimbabwe, 2015.

25. FAO. The Economic Lives of Smallholder Farmers: An Analysis Based On Household Data from Nine Countries; Food and Agriculture Organization of the United Nations: Rome, Italy, 2015.

26. Berkes, F.; Folke, C. Linking social and ecological systems for resilience and sustainability. In Linking Social and Ecological Systems; Berkes, F., Folke, C., Eds.; Cambridge University Press: Cambridge, UK, 1998.

27. Mazvimavi, D. Investigating possible changes of extreme annual rainfall in Zimbabwe. Hyd. Ear. Sys. Sci. 2010, 14, 2671-2679. [CrossRef]

28. Mukwada, G.; Manatsa, D. Geospatial and temporal analysis of drought years in Zimbabwe, 1940-1999. Geogr. Pol. 2013, 86, 313-326. [CrossRef]

29. Mtisi, S.; Prowse, M. Baseline Report on Climate Change and Development in Zimbabwe; Government of Zimbabwe: Harare, Zimbabwe, 2012.

30. Mugandani, T.; Wuta, M.; Makarau, A.; Chipindu, P. Re-classification of agro-ecological regions of Zimbabwe in conformity with climate variability and change. Afr. Crop Sci. J. 2012, 20, 361-369.

31. Nakashima, D.J.; McLean, K.G.; Thulstrup, H.D.; Ramos Castillo, A.; Rubis, J.T. Weathering Uncertainty: Traditional Knowledge for Climate Change Assessment and Adaptation; UNESCO: Paris, France; UN: Darwin, Australia, 2012.

32. Gitay, H.; Bettencourt, S.; Kull, D.; Reid, R.; McCall, K.; Simpson, A.; Krausing, J.; Ebinger, J.; Ghesquiere, F.; Fay, M. Building Resilience: Integrating Climate and Disaster Risk Into Development, The World Bank Group Experience: Main Report; World Bank: Washington, DC, USA, 2013.

33. Mashizha, T.M. Adapting to climate change: Reflections of peasant farmers in Mashonaland West Province of Zimbabwe. Jàmbá J. Dis. Risk Stud. 2019, 11, a571. [CrossRef]

34. Shumba, E.M.; Marongwe, D. The Convention on Biological Diversity: An overview and lessons learnt from the Zimbabwean experience. Int. For. Rev. 2000, 2, 118-122.

35. Gogoi, E.; Bahadur, A.V.; del Rio, C.R. Mainstreaming Adaptation to Climate Change within Governance Systems in South Asia: An Analytical Framework and Examples from Practice; Learning Paper; ACT: London, UK, 2017.

36. Baldwin, K.; Muyengwa, S. Impact Evaluation of Supporting Traditional Leaders and Local Structures to Mitigate Community-Level Conflict in Zimbabwe; A Report to the United States Agency for International Development under USAID; USAID: Harare, Zimbabwe, 2014.

37. Dodman, D.; Mitlin, D. The national and local politics of climate change adaptation in Zimbabwe. Clim. Dev. 2015, 7, 223-234. [CrossRef]

38. Mavhura, E.; Manatsa, D.; Matiashe, M. Adapting smallholder farming to climate change and variability: Household strategies and challenges in Chipinge District, Zimbabwe. Clim. Chang. 2017, 3, 903-913.

39. Wood, G.D. Staying secure, staying poor: The 'Faustian Bargain'. World Dev. 2003, 31, 455-471. [CrossRef]

40. Rusinga, O.; Murwendo, T.; Zinhiva, H. Political implications of building small dams in communal areas of Zimbabwe: The case of Mhakwe dam in Chimanimani District. J. Sustain. Dev. Afr. 2012, 14, 147-157.

41. Sithole, P.; Mbele, T. Fifteen-Year Review on Traditional Leadership, A Research Paper; Human Sciences Research Council: Cape Town, South Africa, 2008.

42. Makumbe, J. Local Authorities and Traditional Leadership; Local Government Working Paper Series No. 2; Community Law Centre, University of the Western Cape: Cape Town, South Africa, 2010.

43. Mamdani, M. Citizen and Subject: Contemporary Africa and the Legacy of Late Colonialism South Africa; David Phillip Publishers: Cape Town, South Africa, 1996.

44. Chanza, N.; De Wit, A. Epistemological and methodological framework for indigenous knowledge in climate science. Afr. J. Indig. Know. Syst. 2013, 12, 203-216.

45. Shoko, S.; Shoko, N. Indigenous Weather Forecasting Systems: A Case Study of Weather Forecasting Indicators of Wards 12 and 13 in Mberengwa District in Zimbabwe. Asian Soc. Sci. 2013, 9, 285. [CrossRef]

46. Mapara, J. Indigenous knowledge systems in Zimbabwe: Juxtaposing postcolonial theory. J. Pan Afr. Stud. $2009,3,139-155$.

47. Bernard, H.R. Research Methods in Anthropology: Qualitative and Quantitative Methods, 3rd ed.; Alta Mira Press: Walnut Creek, CA, USA, 2002.

48. Brazier, A. Climate Change in Zimbabwe: Facts for Planners and Decision-Makers; Konrad-Adenauer-Stiftung: Harare, Zimbabwe, 2015. 
49. Macchi, M. Framework for Community Based Climate Vulnerability and Capacity Assessment in Mountain Areas; ICIMOD: Kathmandu, Nepal, 2011.

50. Ogbonna, C.U. Adaptation to Climate Change in Developing Countries: A Need in the Niger Delta Region of Nigeria. In Implementing Adaptation Strategies by Legal, Economic and Planning Instruments on Climate Change; Albrecht, E., Schmidt, M., Mißler-Behr, M., Spyra, S., Eds.; Environmental Protection in the European Union; Springer: Berlin/Heidelberg, Germany, 2014. [CrossRef] 